\title{
Aprendizaje Cooperativo en el Grado en Educación Infantil. Estrategias para su aplicación en el aula
}

\section{Cooperative Learning in Early Childhood Education Degree. Strategies to apply in classroom}

INMACULADA CONCEPCIÓN OROZCO ALMARIO

ORCID: https://orcid.org/0000-0001-5170-7805

Universidad de Sevilla

Departamento de Didáctica y

Organización Educativa iorozco@us.es

Fecha de recepción: 18/11/2019

Fecha de aceptación: 19/11/2019

DOI: http://dx.doi.org/10.12795/9788447221912.010

Pp.: 246-266 
Resumen

Esta comunicación muestra como a través de un ciclo de mejora e innovación docente, el alumnado de cuarto del Grado en Educación Infantil adquiere los conocimientos y las destrezas necesarias para aplicar el aprendizaje cooperativo en un aula real. Para conseguir este objetivo, en la asignatura Estrategias Innovadoras de Enseñanza, los y las estudiantes no "reciben la información" acerca de qué es el aprendizaje cooperativo y cuáles son cada una de las dinámicas o técnicas, sino que aprenden en qué consisten cada una de ellas partiendo de sus experiencias e ideas previas y poniendo las estrategias en práctica. Los resultados de la evaluación dejan ver que hay avances significativos y el alumnado se siente más preparado cuando "aprende haciendo".

Palabras claves: Estrategias Innovadoras de Enseñanza, Grado en Educación Infantil, Docencia Universitaria, Experimentación docente universitaria, Aprendizaje Cooperativo.

\section{Abstract}

This presentation shows how, through a cycle of improvement and teaching innovation, fourth year university students in Early Childhood Education acquire the knowledge and skills needed to apply cooperative learning in a real classroom. In order to achieve this objective in the subject Innovative Teaching Strategies, students do not "receive the information" about what cooperative learning is and what each of the dynamics or techniques are. Instead, they learn what each of them consists in, starting from their previous experiences and ideas and putting each of the strategies into practice through experiential situations. The results of the assessment exhibit that there are significant advances and the students feel more trained when they learn by doing.

Key words: Innovative Teaching Strategies, Degree in Early Childhood Education, University Teaching, University Teaching Innovation, Cooperative Learning.

Jornadas de Formación e Innovación Docente del Profesorado | № 2 (2019) Esta obra se distribuye con la licencia Creative Commons Reconocimiento-NoComercial-SinObraDerivada 4.0 Internacional (CC BY-NC-ND 4.0.) 


\section{Descripción del contexto de la asignatura}

La asignatura "Estrategias Innovadoras de Enseñanza" es una asignatura optativa de 6 créditos con un solo grupo que pertenece al cuarto curso del Grado en Educación Infantil. Actualmente imparto docencia en un subgrupo práctico, pero este Ciclo de Mejora Docente (CMD, en adelante) se aplica al grupo completo de estudiantes en las sesiones teóricas en compañía de la profesora con quien tengo la oportunidad de compartir la asignatura. Tanto las sesiones teóricas como las prácticas se desarrollan dos veces a la semana con una duración de hora y veinte cada una.

El aula está formada por 33 estudiantes y existe una prevalencia del género femenino. No obstante, a pesar de las barreras arquitectónicas que existen en las aulas asignadas para las sesiones teóricas (mesas y sillas ancladas en el suelo e inamovibles, inexistencia de rampas...) es un espacio rico y diverso compuesto por una gran variedad de estudiantes pertenecientes a distintos grupos de otras asignaturas, que provienen del Grado Superior de Educación Infantil y del Programa de Movilidad SICUE. La gran mayoría reflejan (y demandan) que a lo largo del grado no han tenido momentos para "saber trabajar en equipo" ni conocerse entre sí.

\section{Diseño previo del CMD}

\section{Mapa de contenidos}

El mapa de contenidos adopta una concepción en red porque son múltiples y fuertes las conexiones que se dan entre los contenidos, para que el alumnado consiga comprender desde una mirada holística y sistémica un problema real, complejo y coherente (García-Díaz, Porlán y Navarro, 2017). El mapa refleja que el principal problema sobre el que gira toda la intervención es el siguiente: ¿Cómo 


\section{aplicar el aprendizaje cooperativo en Educación Infantil?}

Esta cuestión irá dando sentido a las clases desde el principio porque las primeras sesiones se dedicarán a explorar en profundidad las ideas previas del alumnado acerca de qué entiende por aprendizaje cooperativo (en adelante, AC) y cuáles han sido sus experiencias con este en la escuela. Una vez abordado, se reflexiona acerca de la relevancia que supone "saber trabajar y convivir en un equipo" para que las oportunidades de aprendizaje sean mayores y cada una de las personas que lo componen se beneficien porque "nadie sale perjudicado".

Como se puede apreciar en el mapa (ver Figura 1), en este ciclo se incluyen contenidos conceptuales, procedimentales y actitudinales, en el que ninguno prevalece sobre otro, ni se aprenderán de acuerdo a un orden estipulado y cerrado. Estos contenidos irán emergiendo de la propia praxis y serán flexibles. No obstante, el contenido procedimental referido a "técnicas y dinámicas" presenta un protagonismo en este CMD dado que será el eje vertebrador de todo el proceso y a partir del cual irán surgiendo en cadena los demás. En otros términos, a través de la puesta en práctica de "las técnicas y dinámicas de AC", el alumnado aprenderá haciendo y recibiendo retroalimentación sobre sus intentos (Bain, 2004) acerca de qué es el AC, cómo se forman los grupos cooperativos, cuáles son los pasos para su intervención (cohesión social, grupos y aplicación de técnicas) y cuáles son los logros que se producen cuando trabajamos cooperativamente (autonomía, creatividad, responsabilidad individual, habilidades sociales, espíritu crítico, atención a la diversidad...).

\section{Modelo metodológico posible}

El modelo metodológico posible posee un carácter constructivista, lúdico, vivencial y activo, dado que las tres principales metas son: 1) que el alumnado aprenda que es el Aprendizaje Cooperativo a partir de sus conocimientos previos y experiencias vividas, 2) aprenda haciendo y en 
relación con sus iguales, y 3) sea consciente de los beneficios que posee el aprendizaje cooperativo frente al competitivo o individualista en cualquier grupo humano.

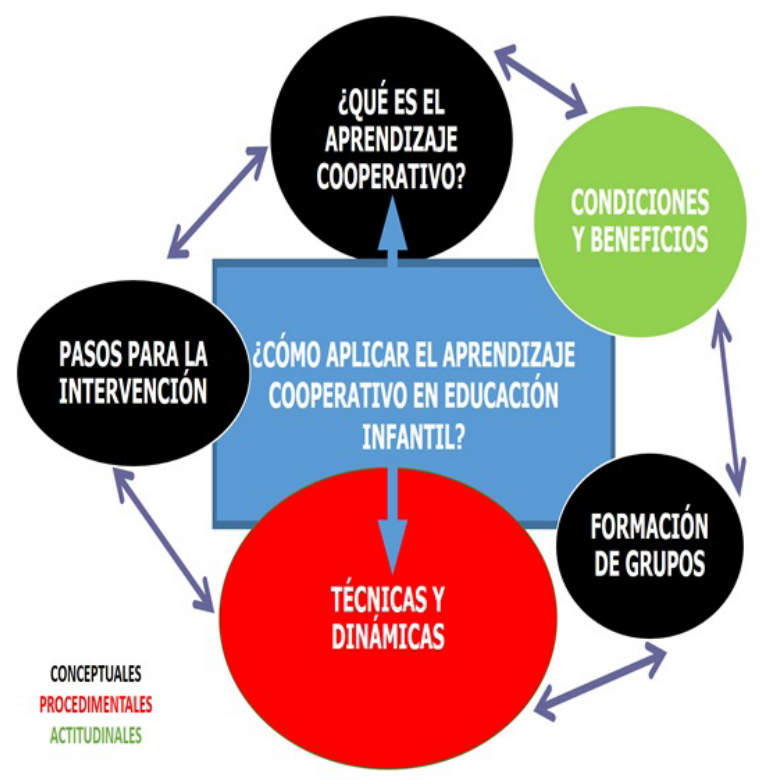

Figura 1. Mapa de contenidos conceptuales, procedimentales y actitudinales

Como se puede apreciar en la ilustración (ver Figura 2), siempre se comenzará conectando con los intereses e inquietudes del grupo, procurando motivarles y creando situaciones donde el aula se reconfigura al salir(me) del centro del proceso de enseñanza-aprendizaje para que los y las estudiantes puedan enfocar su atención en la materia de estudio (Finkel, 2008), dialoguen y expresen sus propias opiniones. Seguidamente, se dará paso a la exploración de los conocimientos previos que irán de la mano de la puesta en práctica (será el engranaje que más tiempo ocupará en las sesiones) casi siempre en pequeños grupos y, en algunos casos, individual para luego hacer puestas en común con el equipo de trabajo. Se procurará cerrar con una síntesis a modo de recapitulación, aunque esto será en función de los tiempos y las necesidades que 
aparezcan en cada una de las sesiones (podrá ampliarse la duración de otra actividad, resolver dudas...).

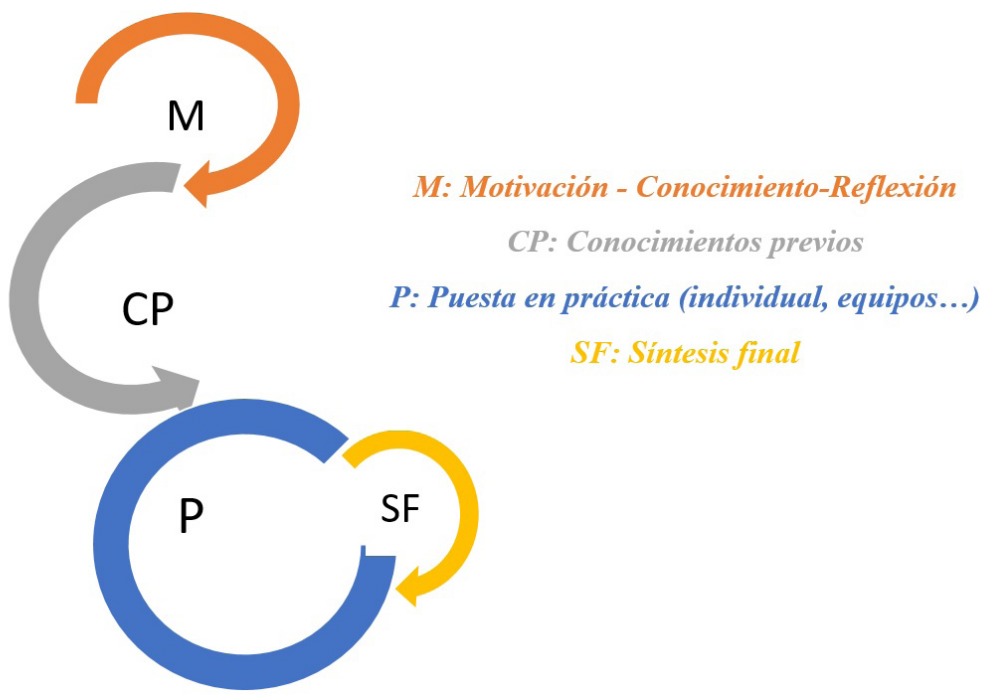

Figura 2. Modelo metodológico posible

\subsection{Secuencia de actividades}

La secuencia de actividades diseñada se recoge en la Tabla 1.

Tabla 1. Secuencia de actividades del CMD

\begin{tabular}{|l|l|l|l|}
\hline Sesión & $\begin{array}{l}\text { Problemas } \\
\text { abordados }\end{array}$ & $\begin{array}{l}\text { Desarrollo de actividades y } \\
\text { temporalización }\end{array}$ & Recursos \\
\hline 1 & $\begin{array}{l}\text { C1,C2,C4 } \\
\text { y C5 }\end{array}$ & $\begin{array}{l}\text { Exploración ideas previas con “El } \\
\text { folio giratorio" [10-15'] } \\
\text { Puesta en común de cada equipo: } \\
\text { ¿Qué sabes del Aprendizaje } \\
\text { Cooperativo (AC)? [15-20'] } \\
\text { Asamblea para compartir nuestras } \\
\text { experiencias y vivencias [40'] }\end{array}$ & $\begin{array}{l}\text { Cartulinas A3 de } \\
\text { colores y medallas } \\
\text { artesanas con } \\
\text { roles de equipo }\end{array}$ \\
\hline
\end{tabular}

Jornadas de Formación e Innovación Docente del Profesorado | № 2 (2019) Esta obra se distribuye con la licencia Creative Commons Reconocimiento-NoComercial-SinObraDerivada 4.0 Internacional (CC BY-NC-ND 4.0.) 


\begin{tabular}{|c|c|c|c|}
\hline 2 & $\mathrm{C} 1, \mathrm{C} 3$ y $\mathrm{C} 4$ & $\begin{array}{l}\text { Visualización vídeo “Aprendamos } \\
\text { de los gansos” [10'] } \\
\text { Puesta en común de cuestiones } \\
\text { acerca del vídeo con “Parada de } \\
\text { tres minutos” [10-15'] } \\
\text { Lectura grupal “Asamblea en la } \\
\text { carpintería” [10-20'] } \\
\text { Demostración y transformación del } \\
\text { texto en equipo y sorteo [5-10’] } \\
\text { Creencias erróneas de A.C [10-20'] } \\
\text { Puesta en común de la creencia } \\
\text { más llamativa [5-10'] }\end{array}$ & $\begin{array}{l}\text { Vídeo } \\
\text { “Aprendamos de } \\
\text { los gansos", Texto } \\
\text { "Asamblea en } \\
\text { la carpintería", } \\
\text { enlace a ruleta } \\
\text { web interactiva } \\
\text { (http://fluky. } \\
\text { io/) y listado de } \\
\text { creencias erróneas }\end{array}$ \\
\hline 3 & $\mathrm{C} 2, \mathrm{C} 3$ y $\mathrm{C} 5$ & $\begin{array}{l}\text { Condiciones para el A.C en equipo } \\
\text { y diseño de actividades a través de } \\
\text { “Palabras compartidas" [20-25'] } \\
\text { Puesta en común [10-15'] } \\
\text { Dinámica de cohesión grupal: } \\
\text { "Entrevista-árbol" [40'] } \\
\text {-Dibujo y pensamiento individual } \\
\text { [10-15'] } \\
\text {-Entrevista en pareja con el árbol } \\
\text { [20-25'] }\end{array}$ & $\begin{array}{l}\text { Hoja explicativa } \\
\text { con cada } \\
\text { condición a } \\
\text { rellenar, folios, } \\
\text { rotuladores, } \\
\text { lápices... }\end{array}$ \\
\hline 4 & $\mathrm{C} 2, \mathrm{C} 4$ y C5 & $\begin{array}{l}\text { Visualización vídeo CEIP que } \\
\text { desarrolla AC [10'] } \\
\text { Debate sobre el vídeo [10-15'] } \\
\text { Breve explicación sobre la } \\
\text { formación de equipos [10-15'] } \\
\text { Debate sobre la organización del } \\
\text { aula a través de imágenes reales de } \\
\text { centros educativas [10-15'] } \\
\text { Elaboración de las normas de la } \\
\text { clase "Grupo Nominal" [30-35'] } \\
\text { Presentación "Saco de dudas" } \\
\text { [10-15'] }\end{array}$ & $\begin{array}{l}\text { Enlace al vídeo del } \\
\text { CEP, diapositivas } \\
\text { con imágenes } \\
\text { reales de aulas, } \\
\text { proyector y } \\
\text { ordenador, tabla } \\
\text { en documento de } \\
\text { Word para insertar } \\
\text { normas, saco } \\
\text { artesanal y tarjetas } \\
\text { en blanco }\end{array}$ \\
\hline 5 & $\mathrm{C} 2$ y $\mathrm{C} 4$ & $\begin{array}{l}\text { Resolución de dudas “Saco de } \\
\text { dudas" [15-20’] } \\
\text { Despegue y aterrizaje [5-10’] } \\
\text { Rally-Robin: ¿Qué te gusta más de } \\
\text { AC? [10'] } \\
\text { Mix-pair-share: ¿Qué te gusta } \\
\text { menos de AC? [10-15’] } \\
\text { Resolución problema matemático } \\
\text { con “lápices al centro" [20-30’] }\end{array}$ & $\begin{array}{l}\text { Saco de dudas, } \\
\text { música y } \\
\text { enunciado } \\
\text { del problema } \\
\text { matemático a } \\
\text { resolver }\end{array}$ \\
\hline
\end{tabular}

Jornadas de Formación e Innovación Docente del Profesorado I № 2 (2019) Esta obra se distribuye con la licencia Creative Commons Reconocimiento-NoComercial-SinObraDerivada Internacional (CC BY-NC-ND 4.0.) 


\begin{tabular}{|l|l|l|l|}
\hline 6 & $\begin{array}{l}\text { C1, C2, C3, } \\
\text { C4 y C5 }\end{array}$ & $\begin{array}{l}\text { Técnica “1-2-4" con problema } \\
\text { matemático [20-30'] } \\
\text { Puesta en común de resultados } \\
\text { "Despegue y aterrizaje" [5-10'] } \\
\text { Concurso sobre AC "Cadena de } \\
\text { preguntas" [20-25'] } \\
\text { Análisis en equipo sobre técnicas } \\
\text { y dinámicas "Programa CA/AC" } \\
\text { aplicables para infantil [30-40'] } \\
\text { Entrega evidencia por correo } \\
\text { electrónico }\end{array}$ & $\begin{array}{l}\text { Enunciado } \\
\text { problema } \\
\text { matemático, } \\
\text { folios y enlace a } \\
\text { "Programa CAC/ } \\
\text { AC (Aprender a } \\
\text { Cooperar/Cooperar } \\
\text { para Aprender)" }\end{array}$ \\
\hline 7 & $\begin{array}{l}\text { C1, C2, C3, } \\
\text { C4 y C5 }\end{array}$ & $\begin{array}{l}\text { Presentación Cuadernos de Equipo } \\
\text { Manipulación de cuadernos reales } \\
\text { en equipo [30-40'] } \\
\text { Reflexión y bocetos de cuadernos } \\
\text { propios en equipo [40'] }\end{array}$ & $\begin{array}{l}\text { Caja con } \\
\text { Cuadernos de } \\
\text { Equipos reales }\end{array}$ \\
\hline
\end{tabular}

\section{Cuestionario inicial-final}

El cuestionario diseñado para los estudiantes contiene cinco preguntas. Estas preguntas son cercanas, abiertas y estimulantes que dan información acerca de los modelos mentales del alumnado, ya que permiten responder con sus propios argumentos (Rivero y Porlán, 2017). Se completó en formato papel de manera presencial y pidiéndole a cada estudiante que se identificara de manera anónima. Se utilizó el mismo instrumento al principio y al final del CMD con el fin de conocer los niveles de aprendizaje, los avances, las dificultades, y así elaborar las propuestas de mejora de la intervención. A continuación, se muestran las preguntas del cuestionario que se vinculan con los problemas y los contenidos de la temática abordada:

1. ¿Qué entiendes por aprendizaje cooperativo?

2. ¿Conoces algunas dinámicas o técnicas de aprendizaje cooperativo?, ¿cuáles?

3. ¿Cuáles crees que son las condiciones para que al aprendizaje sea cooperativo?

4. ¿Consideras que es importante implementar el aprendizaje cooperativo en infantil?, ¿por qué? 
5. ¿Te sientes preparado/a para llevar a la práctica el aprendizaje cooperativo?, ¿por qué?

\section{Aplicación del CMD}

\section{Relato resumido de las sesiones}

\section{Sesión 1: Explorando las ideas previas sobre AC y vivencias}

El hecho de presentar la temática desde sus vivencias y "haciendo" originó un ambiente distendido donde pude apreciar que las opiniones de todos se respetaban y valoraban, y a la vez, se conocían mejor entre ellos. Todas las fases ocuparon un largo tiempo, pero consideré que era necesario para que los próximos contenidos fuesen significativos. Que hubiera un portavoz en el grupo también reforzó el apoyo entre iguales y fue una estrategia útil para escuchar las propuestas en grupos donde la ratio es elevada.

Sesión 2: Cuestionario de ideas previas, "Aprendiendo de los Gansos", "Asamblea en la Carpintería" y desmontamos falsas creencias sobre AC

Al comienzo de la clase, el alumnado comienza a rellenar de manera anónima el cuestionario para explorar las ideas previas (pre). Logro que lo complementen con calma, pero dejándole claro que no "cuenta para nota", sino para que ellos mismos valoren qué sabían al principio y qué han aprendido a lo largo de estas sesiones.

El vídeo fue útil y les hizo pensar, y la técnica simple "Parada de tres minutos" me hizo ver que en el aula hay que ser flexible con los tiempos, y que las técnicas tienen que ajustarse al grupo con el que se trabaja. Me sentí 
plenamente satisfecha con la dinámica a partir del texto "Asamblea en la carpintería", ya que ellos mismos manifestaron que les había gustado el cuento y que lo veían "aplicable a un aula de infantil". Además, aprecié que la motivación de los y las estudiantes aumentó considerablemente al "echar a suertes" la representación del mismo.

Por último, el hecho de tener un portavoz para las creencias del AC facilitaba que las voces de cada grupo se escucharan, pero sentí que no era suficiente tiempo para que todos pudiesen intervenir. Quizá hubiera sido conveniente dejar esta actividad para el próximo día o establecer un tiempo de "exposición" para luego intervenir. La dinámica de las condiciones para el AC no pudo desarrollarse por la falta de tiempo. De nuevo, siento que debería priorizar las actividades.

\section{Sesión 3: Condiciones del AC y dinámicas cohesión social (entrevista-árbol)}

Para que interiorizaran las cinco condiciones de AC, intenté que por equipos pensaran propuestas aplicables a un aula de infantil. Este pequeño problema que se les planteó, aunque ocupó gran parte del tiempo, creo que era necesario para que proyectaran sus ideas hacia la realidad escolar. Quizá hubiera sido adecuado que las ideas estuviesen en la pizarra a través de alguna herramienta tecnológica como Padlet o Menti (para evaluar) y que hubiesen rotado las propuestas entre los pequeños grupos (a través de la técnica del rompecabezas). Sin embargo, surgió un debate interesante y se aprovechó la exposición de cada portavoz para introducir "la teoría" en la conversación.

La segunda fase de la sesión consistió en llevar a cabo la dinámica de cohesión grupal "entrevista-árbol". Los estudiantes valoraron muchísimo que se les diera la oportunidad de conocerse individualmente y entre ellos porque nunca la habían tenido durante los cuatros años de carrera. Esta actividad también se dilató en el tiempo ya que era sencillo visualizar que "estaban deseando conocerse y 
hablar entre ellos". No pudieron presentarse algunas parejas delante del gran-grupo debido al límite de tiempo. Si tuviera que llevar a cabo esta actividad de nuevo, intentaría diseñar teniendo en cuenta que su realización fuera completa. Incluso, si la duración del ciclo de mejora fuera de mayor duración, podría haber planteado que cada día tres o cuatro personas trajeran su "maleta o caja de vida" para presentarse a los demás.

\section{Sesión 4: Visualizamos un vídeo de un centro que implanta AC para identificar técnicas, debatimos sobre la organización del aula y creamos nuestras propias normas.}

El vídeo que visualizaron en clase creo que era demasiado largo y hubiera sido conveniente recortarlo o mostrar tan solo unos minutos para hablar con mayor profundidad sobre lo que aparecía. Ahora, pienso que, incluso hubiera sido buena idea parar el vídeo constantemente con el fin de hacer un concurso y jugar a adivinar los nombres de las técnicas y dinámicas.

El hecho de elaborar nuestras propias normas a través de la técnica "el grupo nominal" también fue valorada positivamente por los y las estudiantes. De hecho, comprendieron que lo esencial no era quién lo decía, sino qué expresaba y cómo la ayuda entre iguales hace posible un buen trabajo.

Al final de la clase, decidí presentar una técnica simple que podrian utilizar en el futuro ( $y$, en mi caso, incorporarla en cualquier asignatura) denominada "saco de dudas". No hubo tiempo para que escribieran y resolvieran las preguntas en equipo, así que tan solo las anotaron de manera individual para resolverlas en el grupo-clase el próximo día. Este cambio me hizo pensar que hay que ajustarse a las circunstancias que acontecen en el día a día. 
Sesión 5- Saco de dudas, técnicas simples de AC (despegue y aterrizaje, Rally Robin y Mix-pair-share)

Cuando se les volvió a presentar "el saco de dudas", hicimos referencia a que no importaba quién había tenido esa duda, sino cómo entre todos podrían buscar la solución.

Por otro lado, tuve la sensación que todas las técnicas que se pusieron en práctica iban muy rápido y seguidas, pero se "lanzaron" con el fin de lograr que las conocieran y tuvieran un amplio abanico de ejemplos.

El hecho de haber utilizado un problema matemático generó conflictos cognitivos que facilitaban el apoyo entre iguales de la técnica "lápices al centro". Sinceramente, en esta actividad vi que el alumnado estaba motivado por resolver el problema y "sacaba lo mejor de sí mismo" para ayudar a cada uno de sus compañeros y compañeras. Aquí comprendí que quejarnos de recursos es una excusa inventada porque no hay mejor recurso que las propias personas. Quizá hubiera sido conveniente haber diseñado algún caso enfocado hacia la infancia, en vez de un problema matemático. No obstante, el objetivo propuesto era que conocieran la técnica y la experimentaran para poder aplicarla, así que creo que se consiguió.

\section{Sesión 6: "1-2-4, cuestionario post y estudio del programa formativo de Aprendizaje Cooperativo"}

La técnica fue un éxito porque no solo se ayudaron entre ellos, sino que creamos un debate donde se reflexionó sobre la competitividad en las escuelas y cómo a través de esta estrategia metodológica se puede prevenir desde edades tempranas. Haciendo uso de la técnica ya conocida de "despegue y aterrizaje" apreciamos visualmente que con ayuda había un mayor número de problemas resueltos. 
Para esta sesión también teníamos planificado la técnica simple "cadena de preguntas" para que fuesen autoevaluándose creando preguntas en pequeños grupos y simular un concurso. No obstante, debido al poco tiempo disponible para pasar el cuestionario final y adentrarnos en la realidad de la etapa de educación infantil, decidimos que trabajaran sobre el programa para que analizaran una por una las técnicas con el fin de ver su utilidad en la infancia. Observamos que estaban un tanto agobiados al pedirle la tarea y el cuestionario, así que fueron combinando ambas. La evidencia de aprendizaje grupal, finalmente, la envió un representante del equipo por correo electrónico después de clases. Aquí fuimos consciente de la flexibilidad a la hora de entregar las tareas y no premiar la rapidez, sino la calidad del proceso.

\section{Sesión 7: Manipulamos los cuadernos de equipo}

La clase se inició entrando al aula con una caja llena de "Cuadernos de Equipo" reales de Educación Primaria para que cada uno de los grupos manipularan, revisaran y comprendieran in situ en qué consiste, cuáles son las partes que lo componen..., etc. La evidencia que se les pidió fue que, a partir de estos, crearan su propio Cuaderno de Equipo para Educación Infantil. De este modo, la sesión fue dedicada a que, por grupos, pensaran y diseñaran cómo iban a hacer su propio cuaderno.

Por último, el cuestionario realizado para evaluar la docencia tuvo que realizarse en algunas sesiones prácticas, en lugar de la parte teórica. Este cuestionario fue útil y me hizo ver que elaborar pocas preguntas, pero breves y con un "gran calado" pueden convertirse en un instrumento valioso (y que no supone apenas tiempo su diseño) para escuchar las voces del alumnado y, en consecuencia, mejorar la docencia. 


\section{Evaluación del aprendizaje de los estudiantes}

La evaluación del aprendizaje del alumnado precisa de un ambiente basado en el diálogo y el respeto, donde se exponen las ideas y los argumentos en confianza (Rivero y Porlán, 2017). Este principio fue el que mantuve a lo largo del CMD teniendo como premisa que la evaluación tenía que ser continua, con instrumentos y herramientas variadas. Por tanto, a partir del diario docente, las fotografias y grabaciones de vídeos de momentos puntuales de las sesiones, la observación participante y la conversación con otra profesora dentro del aula (pareja pedagógica), los cuestionarios de ideas previas (iniciales y finales), las escaleras de aprendizaje, la tabla de evolución de niveles de cada estudiante, las prácticas in situ, las evidencias por correo y un cuestionario sobre la docencia he valorado qué se ha aprendido, qué queda por aprender y qué hay que mejorar en futuras intervenciones.

A continuación, presento, a modo de ejemplo, dos escaleras de aprendizaje (Figura 3 y Figura 4) extraídas a partir de la cuestión segunda y quinta del cuestionario.

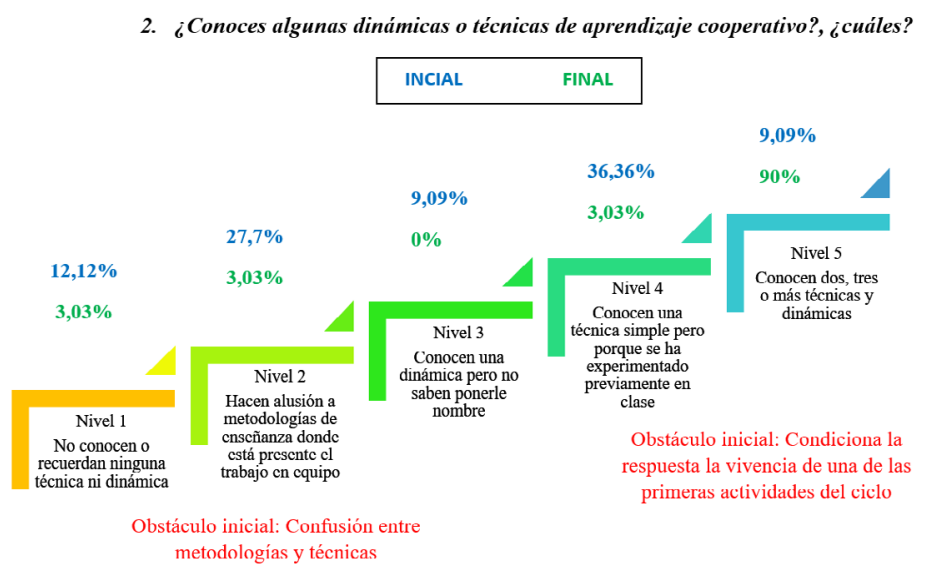

Figura 3. Escalera de aprendizaje sobre la cuestión 2

Jornadas de Formación e Innovación Docente del Profesorado | № 2 (2019) Esta obra se distribuye con la licencia Creative Commons Reconocimiento-NoComercial-SinObraDerivada 


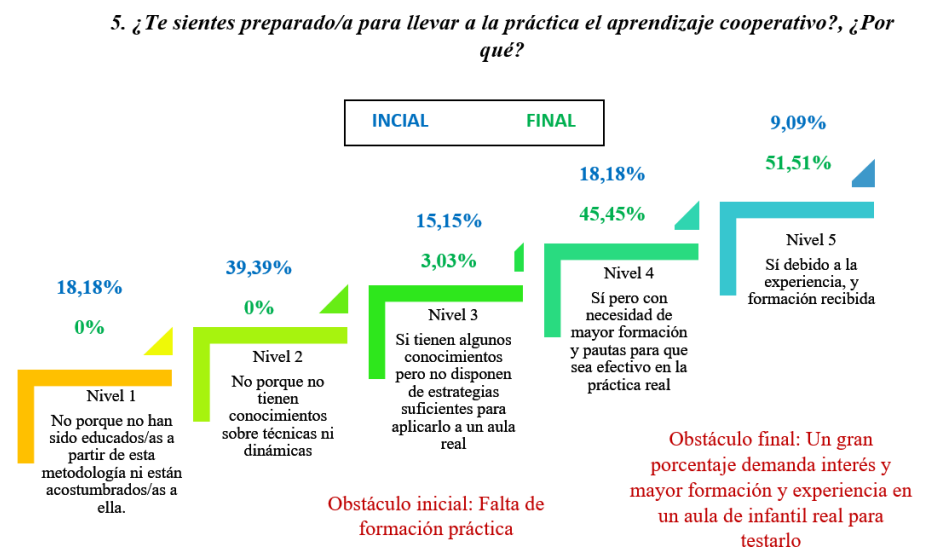

Figura 4. Escalera de aprendizaje sobre la cuestión 5

En la segunda pregunta es donde he obtenido más éxito dado el carácter práctico del desarrollo de las sesiones. Al comienzo no conocían ninguna técnica o dinámica (tan solo mencionaban "el folio giratorio" porque se les había presentado para sondear las ideas previas en la primera sesión antes de rellenar el cuestionario). Al final se refleja que, en general, todos y todas conocen más de tres o cuatro técnicas o dinámicas (y saben en qué consiste cada una de ellas) porque han tenido la oportunidad de vivenciarlas en las clases.

En la quinta pregunta, se aprecia que al inicio casi todos y todas sentían que no estaban preparados para llevar a cabo esta metodología en el aula (bien porque no habían abordado la temática en ninguna asignatura del grado hasta el momento, experimentado el trabajo en equipo real en su vida, desconocimiento de estrategias...) y al final más del 90\% afirma con garantía que sí se sienten con seguridad para aplicarlo en un aula real, pero que le hubiese gustado comprobarlo asistiendo a centros escolares. 
Tabla 2. Cuadro de evolución de cada estudiante en las cuestiones 2 y 5 iniciales y finales

\begin{tabular}{|c|c|c|c|c|}
\hline ALUMNADO & $\begin{array}{c}\text { C2 } \\
\text { INICIAL }\end{array}$ & $\begin{array}{c}\text { C2 } \\
\text { FINAL }\end{array}$ & $\begin{array}{c}\text { C5 } \\
\text { INICIAL }\end{array}$ & $\begin{array}{c}\text { C5 } \\
\text { FINAL }\end{array}$ \\
\hline 1 & N4 & N5 & N2 & N5 \\
\hline 2 & $\mathrm{~N} 2$ & N5 & N2 & N5 \\
\hline 3 & N2 & N5 & N4 & N5 \\
\hline 4 & N4 & N5 & N2 & N5 \\
\hline 5 & N4 & N5 & N2 & N5 \\
\hline 6 & N5 & N5 & N2 & N5 \\
\hline 7 & N4 & N5 & N2 & N4 \\
\hline 8 & N4 & N5 & N1 & N5 \\
\hline 9 & N2 & N5 & N4 & N5 \\
\hline 10 & N4 & N5 & N1 & N3 \\
\hline 11 & N2 & N5 & N2 & N4 \\
\hline 12 & N2 & N5 & N2 & N4 \\
\hline 13 & N5 & N5 & N5 & N5 \\
\hline 14 & N3 & N5 & N2 & N4 \\
\hline 15 & N2 & N5 & N1 & N4 \\
\hline 16 & N3 & N5 & N4 & N5 \\
\hline 17 & N4 & N5 & N1 & N4 \\
\hline 18 & N4 & N5 & N1 & N4 \\
\hline 19 & N4 & N5 & N1 & N4 \\
\hline 20 & N2 & N5 & N2 & N4 \\
\hline 21 & N4 & N5 & N1 & N4 \\
\hline 22 & N4 & N5 & N2 & N4 \\
\hline 23 & N2 & N5 & N1 & N4 \\
\hline 24 & N1 & N5 & N4 & N4 \\
\hline 25 & N4 & N5 & N2 & N5 \\
\hline
\end{tabular}

Jornadas de Formación e Innovación Docente del Profesorado | № 2 (2019) Esta obra se distribuye con la licencia Creative Commons Reconocimiento-NoComercial-SinObraDerivada 4.0 Internacional (CC BY-NC-ND 4.0.) 


\begin{tabular}{|c|c|c|c|c|}
\hline 26 & N1 & N5 & N1 & N4 \\
\hline 27 & N1 & N4 & N4 & N5 \\
\hline 28 & N2 & N5 & N1 & N4 \\
\hline 29 & N2 & N2 & N5 & N5 \\
\hline 30 & N2 & N1 & N5 & N5 \\
\hline 31 & N3 & N5 & N2 & N5 \\
\hline 32 & N1 & N5 & N1 & N5 \\
\hline 33 & N5 & N5 & N4 & N5 \\
\hline \multicolumn{5}{|c|}{ HA LLEGADO AL NIVEL 5} \\
\hline \multicolumn{5}{|c|}{ HA LLEGADO AL NIVEL 4} \\
\hline \multicolumn{5}{|c|}{ HA LLEGADO AL NIVEL 3} \\
\hline \multicolumn{5}{|c|}{ HA LLEGADO AL NIVEL 2} \\
\hline \multicolumn{5}{|c|}{ HA LLEGADO AL NIVEL 1} \\
\hline \multicolumn{5}{|c|}{ SE HA MATENIDO ESTABLE - EN EL MISMO NIVEL- } \\
\hline \multicolumn{5}{|c|}{ HA RETROCEDIDO NIVELES } \\
\hline
\end{tabular}

En lo que respecta al cuadro de evolución del alumnado (ver Tabla 2), debo reflejar que me llena de satisfacción porque deja ver que una gran parte de los y las estudiantes han alcanzado el máximo nivel en cada una de las preguntas del cuestionario. Dada la diversidad de modelos mentales, algunos no han conseguido llegar al nivel cinco, pero también prevalece el nivel cuatro incluso el tres. Esto me hace pensar que cada uno tiene su ritmo de aprendizaje pero que, al menos, una gran parte ha conseguido avanzar en sus creencias, conocimientos, habilidades y destrezas. Por otra parte, también me parece curioso que existan regresiones (especialmente en la cuestión número tres) y quizá pueda deberse al poco tiempo dedicado a la actividad que se llevó a cabo concretamente para dicho problema. Evidentemente estas regresiones no creo que se deban especialmente al alumnado, sino a la manera en la que he intentado transmitir dichos contenidos. 


\section{Evaluación del CMD puesto en práctica}

\section{Cuestiones a mantener y cambios a introducir para un futuro Ciclo de Mejora más amplio}

Las cuestiones sobre qué ha funcionado, qué no y qué incorporaré en mi práctica, se confeccionan a partir de la lectura y reflexión de las respuestas de los y las estudiantes a un cuestionario que realizaron sobre la autoevaluación de la docencia. A través de un código QR que escaneaban con el móvil, accedieron a un formulario de Google Docs y respondieron a cuatro preguntas:

1) ¿Qué es lo que más te ha gustado?, ¿por qué?

2) ¿Qué es lo que menos te ha gustado?, ¿por qué?

3) Recomendaciones y aspectos a mejorar

4) Es el momento de añadir, si quieres, algo que no se haya abordado en las anteriores preguntas y te apetezca.

Por tanto, las cuestiones a mantener para un futuro CMD serían las siguientes:

1) Las actividades donde el alumnado tiene un rol activo y aprende haciendo, en movimiento

2) Plantear dinámicas de cohesión grupal para que se cree un clima agradable y de confianza

3) Fusión entre teórica y práctica. No dedicar la mayoría del tiempo a explicar y hacer pequeñas prácticas, sino que al hacer las prácticas se entiende la teoría.

4) Partir de sus experiencias escolares para repensar la necesidad de aprender cualquier temática

5) Traer recursos reales de centros educativos para encontrar sentido a lo que se aprende

6) Elaboración de un cuestionario inicial y final para analizar los obstáculos y logros alcanzados en el alumnado a través de las escaleras de aprendizaje. Asimismo, este ha permitido reflexionar sobre aquellos diseños que no eran accesibles 
7) Diseño de un cuestionario para evaluar la docencia con respuestas en anónimo. Se sentían libres en la respuesta, sin miedos. A partir de aquí siento que este debería hacerse después de cada sesión (con formatos distintos y cuestiones diferentes pero que analicen las fortalezas, las debilidades y los puntos a mejorar)

8) Tener presente la flexibilidad de los tiempos y ritmos en función de las necesidades que demandaba el grupo

9) Utilización de herramientas interactivas y tecnológicas para incrementar la motivación

10) Presencia de dos docentes en el aula para conversar "sobre la marcha lo que está ocurriendo" y crear nuevas ideas

11) Emplear grabaciones de vídeos y fotografias para analizar las dinámicas y actividades diseñadas.

"De las cosas que más me han gustado ha sido compartir tiempo y momento con mis compañeros/as y compartir momentos con otros nuevos a los que jamás hubiese pensado hablarle si no hubiese sido por las prácticas. Además de aprender diversas técnicas de aprendizaje cooperativo" (Respuesta del alumnado a la cuestión 1)

Por otra parte, los cambios a introducir para un futuro CMD serían:

1) Formato del cuestionario de ideas previas pre y post en papel debido al tiempo invertido en su análisis y categorización. Además, hubiera sido más sencillo, cercano y accesible para el alumnado a través de un formulario a través de Google Docs o Kahoot.

2) Agobio en momentos puntuales por querer que vivieran más dinámicas en vez de priorizar solo en algunas claves.

3) Contacto con un aula real para que el alumnado lleve a la práctica las técnicas y dinámicas aprendidas. 
"Debido a la falta de tiempo algunas actividades se han llevado a cabo de manera muy rápida y apenas hemos podido disfrutar de ellas."

(Respuesta del alumnado a la cuestión 2)

\section{Principios Didácticos y aspectos de la experiencia que se pretenden incorporar a toda la práctica docente habitual}

Mis principios didácticos se fundamentan en actividades del aula que sean experiencias donde el alumnado aprenda haciendo y en relación con los demás (por ejemplo, si vamos a explicar los tipos de escuelas que existen, en lugar de explicarlas, que sean los y las estudiantes los que investiguen por equipos sobre ellas y creen materiales acordes a cada una). Esto supone, además, vincular constantemente los contenidos a partir de problemas que nacen en la realidad escolar, así como flexibilizar los tiempos.

"Continuaría realizando más prácticas ya que pienso que es como mejor se aprende" (Respuesta del alumnado a la cuestión 3)

También se basan en la realización de cuestionarios docentes de exploración de ideas (pre y post) del alumnado durante cada temática para detectar los obstáculos y reajustar los diseños de aula y mejorar las prácticas. Siempre tendré presente el anonimato para que los y las estudiantes vean que "no cuentan para la nota ni son para calificarles". Asimismo, incorporaré una variedad de instrumentos y herramientas para evaluar con el fin de tener una visión holística del proceso (diarios docentes, cuestionarios, tareas de clases, evidencias, herramientas tecnológicas, fotografias, vídeos, reflexiones de estudiantes...). 


\section{Referencias bibliográficas}

Bain, K. (2004). Lo que hacen los mejores profesores universitarios. Valencia: Universitat de Valencia.

Finkel, D. (2008). Dar clase con la boca cerrada. Valencia: Universitat de Valencia.

García-Díaz, E., Porlán, R., y Navarro, E. (2017). Los fines y los contenidos de enseñanza. En Porlán (Coord.). Enseñanza Universitaria. Cómo mejorarla. (pp. 55-72). Madrid: Morata.

Rivero, A., y Porlān, R. (2017). La evaluación en la enseñanza universitaria. En Porlán (Coord.). Enseñanza Universitaria. Cómo mejorarla. (pp. 74-91). Madrid: Morata.

Jornadas de Formación e Innovación Docente del Profesorado | № 2 (2019) Esta obra se distribuye con la licencia Creative Commons 